\title{
Neurosyphilis: the most common things are most common
}

\author{
MARTIN D TALBOT* AND ROBERT S MORTON† \\ From the *Department of Genitourinary Medicine, Royal Hallamshire Hospital, and +Subdepartment of \\ History of Medicine, University of Sheffield, Sheffield
}

SUMMARY Reports published in the past twenty years include many purporting to show, without much reason, that classic presentations of neurosyphilis are the exception rather than the rule. We join the few who take another view, and discuss here the reasons underlying the conflict of opinions.

\section{Introduction}

In 1870 Jonathan Hutchinson reported atypical cases of neurosyphilis. ${ }^{1}$ The great writers on syphilis earlier this century also noted such cases. ${ }^{2-4}$ Their clinical observations were ably supported by the laboratory work on some 6000 specimens of cerebrospinal fluid (CSF) by Dattner, who was able to show that neurosyphilis begins in the secondary stage and has a long latent period and that cellular and chemical changes in the CSF clearly reflect the way and length of time that the nervous system has been affected. ${ }^{5}$ In addition, he showed that arrest of the disease by time or treatment is confirmed by CSF changes returning to normal in an orderly but out-of-phase manner.

That neurosyphilis is still with us and may present unusual features is shown by recent reports, ${ }^{6-11}$ which were considered important enough to provoke editorial comment. ${ }^{12-14}$ Only one report, which listed 17 cases presenting with classic symptoms, signs, and findings in the CSF, has been published. ${ }^{15}$ Two questions arise. Firstly, how is neurosyphilis defined today? and, secondly, are there any acceptable figures, past or present, to define the proportions of atypical to classic cases? The answer to the second question is "No". Answering the first question is more difficult.

Hooshmand et al diagnosed neurosyphilis 241 times in 15 years. ${ }^{16}$ They gave their diagnostic criteria

Address for reprints: Dr M D Talbot, Department of Genitourinary Medicine, Royal Hallamshire Hospital, Glossop Road, Sheffield S10 $2 \mathrm{JF}$

Accepted for publication 2 July 1984 as: (a) positive fluorescent treponemal antibody (absorbed) (FTA-ABS) blood test results with ophthalmic or neurological findings suggestive of neurosyphilis; (b) positive FTA-ABS results in blood and CSF with abnormal CSF white cell count and no evidence of bacterial or viral meningitis; or (c) positive FTA-ABS tests results in blood and CSF with progressive neurological symptoms and signs (when other aetiological factors could be excluded) and a temporary increase in the CSF white cell count after treatment or an appreciable clinical improvement after treatment with penicillin. (It has long been recognised that an increased white cell count may simply follow lumbar puncture and persist for three weeks; also that white cell counts above the accepted upper limit of normal $\left(5 \times 10^{6}\right.$ cells $\left./ \mathrm{l}\right)\left(5 / \mathrm{mm}^{3}\right)$ may occur in older, healthy people).

Over $40 \%$ of the 241 patients of Hooshmand et al had symptoms unrelated to syphilis and were found incidentally to have abnormal ocular changes or absent deep tender reflexes as well as abnormal findings in the blood and CSF that were compatible with neurosyphilis. Although the most common clinical findings were absent ankle jerks and pupillary changes, which are not infrequent in healthy old age, no mention was made of the patients' ages. Like Dewhurst, ${ }^{17} 18$ the authors felt that the clinical picture was not always compatible with the CSF changes. Other workers who used the diagnostic criteria of Hooshmand et al showed shortcomings in their diagnoses. For example, no attempt was made to define the duration of infection, the way the nervous system was affected, or previous antibiotic treatment. ${ }^{19}$ 
We think that the view that neurosyphilis presents today in an atypical manner is untenable and not proved. We present three recently diagnosed cases of neurosyphilis.

\section{Case reports}

\section{CASE 1 TABOPARESIS}

A 58 year old, married, retired electrician with positive serological tests for syphilis was referred by a general physician. For 12 years he had been under the care of a psychiatrist with a depressive illness that had started as a mild affective disorder in the late 1960s. The depression was resistant to standard drug treatment and electroconvulsive therapy. One year before his referral, he had received penicillin $V$ $250 \mathrm{mg}$ orally four times daily for ten days to treat a thrombophlebitic episode affecting his legs. Three months before referral he "blacked out" momentarily, and four days before his admission to hospital he sustained a transient but dense left hemiplegia. His wife acknowledged that he had recently become more forgetful. When he was noted to have Argyll-Robertson pupils, his "transient ischaemic attack" was diagnosed as a congestive attack of general paresis of the insane. Apart from the pupillary abnormality, hyporeflexia in the legs and posterior column signs were also noted. His affect was flat, facies expressionless, and voice slow. His blood pressure was $130 / 80 \mathrm{~mm} \mathrm{Hg}$ and the fundi were normal. His peripheral vascular system was clinically satisfactory.

The full blood count, blood urea concentration, and skull and chest radiographs were normal. Although the rapid plasma reagin (RPR) test gave negative results, the Treponema pallidum haemagglutination assay (TPHA) gave positive results at a titre of 1/1280 and the FTA-ABS gave positive results. The CSF was clear and contained $1 \times 10^{6} / 1\left(1 / \mathrm{mm}^{3}\right)$ white cells. The total protein concentration was raised, however, at $0.75 \mathrm{~g} / \mathrm{l}$, the IgG concentration was $0.126 \mathrm{~g} / \mathrm{l}$ (laboratory reference range $0 \cdot 005-0.065 \mathrm{~g} / \mathrm{l}$ ), the total globulin concentration was noticeably increased, and the Lange curve was 124553111 . The CSF gave positive results in the TPHA at a titre of $1 / 160$ and positive results in the FTA-ABS test.

A full course of $20 \mathrm{MU}$ procaine penicillin was given intramuscularly over three weeks. After two years his pupils had regained some reactivity and the posterior column sensation had returned. Although his mental state had not worsened, however, it had not improved. He consistently refused follow up lumbar puncture, but the serological tests remained at their previous level.

The patient was heterosexual and had probably been infected by one of several casual relationships while a soldier in the army occupying Germany in the late 1940s. He had married after that time, and his wife's serological test for syphilis was currently negative. There were no children. Our opinion is that, although the course of oral penicillin before his presentation had altered some of the test variables, the whole picture (historical, clinical, and investigational) supported a diagnosis of classic taboparesis.

\section{CASE 2 TABES DORSALIS}

A 54 year old housewife was admitted to a local hospital for investigation of weight loss. Unexpected central nervous system findings of a left ArgyllRobertson pupil, hypotonia and areflexia in the legs, loss of position and vibration sense over the ankles and sternum, and loss of deep pain sensation in the right tendo Achillis, prompted serological testing. The Venereal Disease Research Laboratory (VDRL), TPHA, and FTA-ABS tests all gave positive results, the first two at titres of $1 / 16$ and $1 / 5120$ respectively. Examination of the CSF showed a clear colourless fluid with a raised IgG concentration of $0.0815 \mathrm{~g} / \mathrm{l}$, which gave positive results in the FTA-ABS test and positive results in the TPHA at a titre of $1 / 320$. The total protein concentration and cell count were within normal limits, and the CSF gave negative results in the VDRL test. Full blood count, serum vitamin $B_{12}$, and folate concentrations were within normal limits and a chest radiogram showed no abnormality. She was diagnosed as having tabes dorsalis and treated with $20 \mathrm{MU}$ procaine penicillin parenterally over three weeks. After three months her clinical condition was unchanged and she had not yet had a repeat lumbar puncture.

For three years before presentation she had suffered from attacks of bronchitis in the winter and had received three one week courses of antibiotics (ampicillin and tetracycline) by mouth. Her husband had died of renal failure secondary to tabes dorsalis in a local hospital 12 years earlier. Our patient had not been offered an examination, nor had our opinion been sought on the husband's condition. There were no children.

We consider that this woman's classic tabes dorsalis had been established for too long to have been modified by her fortuitous antibiotic treatment, and that the CSF findings simply reflect the resolution that Dattner would have predicted.

\section{CASE 3 ACUTE SYPHILITIC TRANSVERSE MYELITIS}

A 34 year old homosexual man presented to the neurological unit via the emergency room of this hospital complaining of weakness of the legs. He had 
been well until three days before his presentation, when he began to drag his legs and noticed numbness in both legs below the waist. He had been unable to walk for 24 hours before his admission. For three days he had noted poor bladder control; he knew when his bladder was full, but had difficulty in starting micturition and had no sensation of passing urine. Apart from manifest anxiety, his general clinical examination was normal. In the central nervous system, however, muscle tone was decreased in both legs and power was reduced to grade III. Deep tendon reflexes in the legs were brisk and equal, and the plantars were extensor. The lower abdominal reflexes were absent. Coordination, power, tone, and reflexes in the arms were sound. There was a sensory level to touch and pin prick below the level of the ninth thoracic vertebra. A myelogram showed no abnormality.

The serum gave positive results in the VDRL test (at a titre of $1 / 8$ ), the TPHA (at a titre of $1 / 1280$ ), and the FTA-ABS. The CSF was sterile and contained $100 \mathrm{~g} / 1$ of protein. At the time of the lumbar puncture syphilis was not suspected and so no other tests were ordered. Treatment with adrenocorticotrophic hormone (ACTH) was started in the belief that the patient was suffering from disseminated sclerosis. After receipt of the serological results a second sample of CSF was obtained, which showed a total white cell count of $50 \times 10^{6} / 1\left(50 \mathrm{~mm}^{3}\right)(90 \%$ lymphocytes), a protein concentration of $100 \mathrm{~g} / \mathrm{l}$, a first zone Lange curve, and positive results in the TPHA (at a titre of 1/1280) and in the FTA-ABS test. Treatment with penicillin was started in the form of crystalline penicillin $5 \mathrm{MU}$ intravenously daily to a total of $60 \mathrm{MU}$, which gave a pleasing clinical response. After 10 days he was walking unaided and had normal bladder function.

After three months he was walking with a widebased gait with some residual spastic paraparesis and had normal micturition. After six months, the following test variables were observed: the serum gave a negative reaction in the VDRL test and the titre in the TPHA had dropped to 1/320; the CSF had less than $1 \times 10^{6} / 1\left(1 / \mathrm{mm}^{3}\right)$ white cells, a protein concentration of $10 \mathrm{~g} / \mathrm{l}$, a flat Lange curve, and positive results in the TPHA (at a titre of $1 / 80$ ) and the FTA-ABS test. At eighteen months, his gait was normal and his serology results had not changed.

He had had only one sexual contact in this country, who was diagnosed as suffering from early latent syphilis at another clinic one month later. Our patient had often travelled to the Middle and Far East, where he had had contact with multiple sexual partners. He gave no history of sexually transmitted disease (STD) or treatment with antibiotics and no history consistent with early syphilis. There was no scar of a primary lesion.

In our opinion this was a classic presentation of syphilitic meningomyelitis.

\section{Discussion}

Various developments may affect the primary presentation of patients with neurosyphilis-such as, earlier consultation by patients with minimal symptoms, increasing expectations of and use of medical facilities by patients, and the widespread use of the sensitive and specific serological tests for screening that are currently available. Two factors worthy of detailed attention include habits of prescribing antibiotics and the development of new CSF testing procedures.

Atypical presentation may result from "happenstance" antibiotic treatment-that is, treatment with antibiotics that happen to be given to a patient with unidentified syphilis in circumstances ("stance") unassociated with the condition. Thus neurosyphilis may be partly or completely arrested at any stage of its development and so present symptoms and signs in other than the classic form. ${ }^{16} 20-22$

The adaptation of serological tests for syphilis for use in the CSF has been disappointing. The VDRL test has proved negative in a third to a half of samples of CSF from patients with clinically active neurosyphilis. ${ }^{23}$ Only TPHA titres over $1 / 2560$ in the CSF are considered to be suggestive of active neurosyphilis, as false positive results may occur with high albumin quotients (see below). Much the same may occur with the $T$ pallidum specific IgM test in the CSF. A raised titre suggests local antibody production in the central nervous system, but allowance has to be made for increased diffusion from the serum. ${ }^{24}$

CSF white cell counts and measurements of total protein concentration above the upper limit of normal indicate no more than an inflammatory process. In the presence of other evidence of syphilis, however, they are reliable in defining the activity and type of neurosyphilis, and their reversal to normal is a measure of its resolution.

Several laboratory variables have been studied recently to make measuring IgG in CSF a more reliable indicator of the production of local antibody. They all attempt to correct for impairment of the blood brain barrier or increased diffusion across the barrier due to high serum concentrations of immunoglobulin. For example: 
1. The albumin quotient

$=\frac{\mathrm{CSF} \text { albumin concentration }(\mathrm{mg} / \mathrm{dl}) \times 1000}{\text { serum albumin concentration }(\mathrm{mg} / \mathrm{dl})}$

2. The IgG quotient

$=\frac{\mathrm{CSF} \text { IgG concentration }(\mathrm{mg} / \mathrm{dl}) \times 1000}{\text { serum } \mathrm{IgG} \text { concentration }(\mathrm{mg} / \mathrm{dl})}$

3. The $\operatorname{IgG}$ index $=\frac{\text { IgG quotient }}{\text { albumin quotient }}$

The normal IgG index is $0 \cdot 5$. Values above this indicate IgG production within the blood brain barrier.

These ratios, however, are as subject to errors in test procedure and to clinical misinterpretation as the estimation of total protein concentration, Pándy's test, and Lange's test. ${ }^{17-19} 2526$ The limitations of the old tests are well recognised. More recently polyacrylamide gel electrophoresis has been found to be more sensitive in CSF estimations, as actual classes of abnormal antibody can be identified when gross concentrations of immunoglobulin are within normal limits. ${ }^{24}$ Further experience is clearly needed. For the future, perhaps the most sensitive and specific test will be developed by adapting oligoclonal immunofixation of antitreponemal IgM bands to CSF treponemal antigens using the "immune blotting" technique (E J Thompson, personal communication).

The pitfalls awaiting the unwary are many. As well as taking a general medical history including that of treatment with antibiotics, doctors should take a sexual history, including sexual orientation and any earlier diagnoses and treatment of STD. Investigation of a spouse may prove helpful. In women, clinical records of antenatal care (like finding the scar of a primary chancre in men) may help to date the duration of infection and the role of any antibiotic treatment.

Similar views to ours have been expressed by other workers. ${ }^{23}{ }^{27} \mathrm{We}$ would join them in a plea for a more thoughtful, rational, and painstaking approach to the diagnosis of neurosyphilis.

\section{References}

1. Hutchingson J. Syphilis. London: Cassell, 1867.

2. Power D'A, Murphy JK. A system of syphilis. London: Oxford Medical Publications, 1914.

3. Stokes $\mathrm{JH}$, Beerman $\mathrm{H}$, Ingraham NR. Modern clinical syphilology. Philadelphia: WB Saunders, 1945.

4. Merritt HH, Adams RD, Solomon HC. Neurosyphilis. New York: Oxford University Press, 1946.

5. Dattner B. The management of neurosyphilis. London: Heinemann, 1944.

6. Davis WE, Sperry S. Bell's palsy and secondary syphilis. Ann Neurol 1978;4:378-80.

7. Balkany TJ, Dans DE. Reversible sudden deafness in early acquired syphilis. Ann Otolaryngol. 1978;104:66-8.

8. Hoffman BF. Neurosyphilis in a young man. Can J Psychiatry $1981 ; 26: 68-70$.

9. Wetherill JH, Webb HE, Catterall RD. Syphilis presenting as an acute neurological illness. $\mathrm{Br}$ Med J 1965; i: 1157-8.

10. Nadol JB. Hearing loss of acquired syphilis. Laryngoscope 1975; 85:2.

11. Rothenberg R, Becker G, Weit R. Syphilitic hearing loss. South Med J 1979; 72: 118-20.

12. Anonymous. Neurosyphilis again. Br Med J 1981;283:263-4.

13. Anonymous. Never forget syphilis. Br Med J 1975; ii: 460-1.

14. Anonymous. Puzzling cases of syphilis. Br Med J 1972; iii:66-7.

15. Luxon L, Lees AJ, Greenwood RJ. Neurosyphilis today. Lancet 1979; i:90-3.

16. Hooshmand $\mathrm{H}$, Escobar MR, Kopf SW. Neurosyphilis. JAMA 1972; 219:726-79.

17. Dewhurst K. Atypical serology in neurosyphilis. $J$ Neurol Neurosurg Psychiatry 1968;31:496-500.

18. Dewhurst $K$. The composition of the cerebrospinal fluid in the neurosyphilitic psychoses. Acta Neurol Scand 1969; 45: 119-23.

19. Joyce-Clark N, Molteno ACB. Modified neurosyphilis in the Cape Peninsula. S Afr Med J 1978;1:10-4.

20. Anonymous. Modified neurosyphilis. $\mathrm{Br}$ Med J 1978; ii: 647-8.

21. Morton RS, Harris JRW, Eds. Recent advances in sexually transmitted diseases. No 1. Edinburgh: Churchill Livingstone, 1975: 107-11 and 162-7.

22. Allan SG, Smith CC, Downie AG. Neurosyphilis revisited. Scott Med J 1983; 28:57-61.

23. World Health Organisation. Treponemal infections. WHO Tech Rep Ser. 1982; No 674: 1-34.

24. Thompson EJ, Johnson MH. Electrophoresis of CSF proteins. Br J Hosp Med 1982; 28:600-8.

25. Gowardman MG. Problems of diagnosis and management of neurosyphilis in a psychiatric hospital. Report of 10 cases. NZ Med J 1970; 72: 178-82.

26. John JF, Cuetter AC. Spinal syphilis: the problem of fluorescent treponemal antibody in the cerebrospinal fluid. South Med J 1977; 70:309-11.

27. Harris JRW, ed. Recent advances in sexually transmitted diseases. No 2. Edinburgh: Churchill Livingstone, 1981:73-4. 